\title{
A LITERATURE REVIEW: PARENTAL NEEDS IN THE NEONATAL INTENSIVE CARE ROOM
}

\author{
Sri Hendrawati, Fanny Adistie, Nenden Nur Asriyani Maryam \\ Faculty of Nursing, Universitas Padjadjaran, Bandung, Indonesia \\ Correspondence: sri.hendrawati@unpad.ac.id
}

\begin{abstract}
Infants' hospitalization in the neonatal intensive care unit (NICU) adversely affect infants and parents. Many activities have been developed to minimize the negative impact of infants' hospitalization, one of them is applying the family centered care method. The first step of the method is to identify parent' needs. This literature review is aimed to identify the needs of parents with critically ill infants in the neonatal intensive care unit. Articles were collected from several databases including Medline, CINAHL, EBSCOhost, Google Scholar, PubMed, and Proquest. The keywords were critically ill infants, family centered care, the needs of parents, and neonatal intensive care unit, qualitative, and quantitative studies. The articles reviewed were only articles with full text, written in English, and published during period 2004 to 2017. The study was criticized by the author using the Critical Appraisal Tool from JBI (Joanna Briggs Institute). 10 articles that related specifically to parental needs were discovered. Needs of parents with critically ill infants, including the needs to (1) have a positive acceptance and caring attitude of nurses towards infant and parents; (2) get an accurate information, effective communication, and parents' involvement in decision making regarding to the condition of the infant; (3) have confident and believe that infant get the best care; (4) have an adequate contact with infant; (5) have opportunity in caring for the infant with the guidance and supervision of nurses; and (6) obtain comfortable neonatal intensive care unit environment. Each parent has a different priority of their needs. This needs identification would help nurses in integrating parents' need for the family centered care approach. As a result, parents would meet their needs, feel satisfied, and improved the infants' quality of life.
\end{abstract}

Keywords: Neonatal Intensive Care Unit, Parental Needs

\section{INTRODUCTION}

Various reasons were identified related to causes of neonates' hospitalization in NICU including prematurity, low birth weight, sepsis, difficulty in breathing, or respiratory failure. Newborn care in the NICU would spend several weeks to several months (Mundy, 2010). Infants would be exposed to various environments and stimulated by various procedures. These procedures would have a negative impact on babies and their parents.

Babies who were hospitalized especially in NICU, they would have a risk of getting health problems such as infections, hospitalization stress, and growth and development problems. Environmental conditions and medical procedures during the critical phase contributed to babies' growth and developmental issues. When babies had growth and development problems, it would be affected by physical, emotional, cognitive, or social aspects. It may also treat the neonatal quality life (Vance, 2011). 
Infant in the NICU would be a crisis situation for their parents which might result in psychological problems including stress, anxiety, depression, and even posttraumatic stress (Cleveland, 2008). This in line with research conducted by Maghaireh, Abdullah, Chong, Chua, and Kawafha (2017) in Jordan found that parents with infants in the NICU had psychological problems including stress, anxiety, depression, and sleep disorders. The study also showed that mothers' level of stress was higher than father. This may happen because parents' psychological conditions were not ready to have a baby with a critical illness. Parents may be disappointed, they may have feelings of guilt, failure, despair, anger, helplessness, and loss of self-esteem. According to Shaw et al. in Cleveland (2008), the parental stress begins when they separated with a newborn; inability to help and care for the baby; inability to protect the baby from pain; the baby used many tools in the NICU, and the baby was in critical conditions. A study conducted by Maghaireh et al. (2017) found that the behavior and appearance of infants at the time of admission to the NICU were the greatest sources of stress, while the sights and sounds of the NICU's tools were the lowest sources of stress. The results of this study in line with Musabirema, Brysiewicz, and Chipps (2015's study in Rwanda which states the same trend. Musabirema et al. (2015) also showed that parents' level of the stress would be influenced by the age of parents, level of education, occupation, and birth weight of the baby.

One action to minimize the negative impact of a baby in the NICU for both infants and parents were family centered care application (FCC). The FCC is a model of infant care in the NICU, nurses involve parents in caring the sick babies based on guidance and direction from nurses (Mattsson, Forsner, Castre'n, \& Arman, 2013). This model was developed based on a philosophy that parents have a significant influence on children's health (Mundy, 2010; Trajkovski, Schmied, Vickers, \& Jackson, 2012; Hiromi, 2012). In this model, the child is seen as part of an inseparable parent (Mattsson et al., 2013).

The FCC involved parents from passive roles to actively participate in caring for their children (Akbarbegloo, Valizadeh, \& Asadollahi, 2009; Soury-Lavergne et al., 2011; O'Brien et al., 2013). Various studies found that the FCC application was relatively safe and easy. In addition, this model has proven in increasing baby's weight, decreasing infants' behavioral of stress, improving welfare and bonding attachment 
between mother and baby, reducing stress experienced by parents related to baby care, lower length of stay (LOS), and helping parents to be more confident and competent in caring for her baby after returning home (Sikorova \& Kucova, 2012; Skene, Franck, Curtis, \& Gerrish, 2012; Byers et al., 2012; O'Brien et al., 2013). The application of FCC was expected to also improve the quality of life of neonates.

The first step in applying the FCC model in the neonatal intensive care unit was to identify parents' need (Alves, Severo, Amorim, Grande, \& Silva, 2016). According to Ward (2001), parents' need was divided into 5 aspects, namely: the need for information, the need for assurance, the need for proximity, the need of comforts, and the need of support. When the needs of the parents were identified, then nurses would provide an appropriate support for parents in meeting their needs. Parents who met their needs would improve the quality of care in the NICU room, for babies, parents, and their families. In opposite, improper responses to parental needs, would cause parents' anxiety, stress, fear, and confuse (Ward, 2001).

Nurses' perspective of the most priority parents' need, may differ with parents' actual needs. According to Vaškelytè and Butkevičienè's (2010) study found that there was a significant difference between parents and nurses' perception of the fulfillment of the needs of parents in the neonatal intensive care room. Therefore, it may be difficult for nurses to have a correct identification of parental needs. The identification of parental needs is an important step for nurses in the NICU before applying the FCC model (Cleveland, 2008; Mundy, 2010). The purpose of this literature review was to identify the needs of parents with critically ill babies in the neonatal intensive care unit. All the articles in this literature review were analyzed and the main question was what are the needs of parents with critically ill babies in the NICU?

\section{METHODS}

This literature review approach used to collect and analyze research articles. It was carried out both qualitative and quantitative research. The aim of this literature review was to identify the needs of parents with critically ill infants in neonatal intensive care. There are several criteria in this literature review, including 1) Type of participant: parents with critically ill infants who were treated in intensive care; 2) Type of intervention: infant in NICU; 3) Type of outcome: this review considers studies that 
informed parents' needs, experience, stress levels, and involvement; and 4) Study type: descriptive and qualitative research.

The articles were obtained from several electronic databases including Medline's, CINAHL EBSCOhost, Google Scholar, PubMed, and Proquest. The keywords were critical ill neonates, family centered care, the needs of parents, and neonatal intensive care units. All keywords linked using Boolean "OR" to find as many quotes as possible. And use "AND" which used to increase the specificity or relevance of quotations. The goal of this strategy was to find published research.

The articles that included in this review were published from 2004 to2017. Those articles discussed the parental needs, full text, English articles, specific to the needs of parents in the neonatal intensive care room, and specific to the main questions of the review.

\section{RESULTS}

According to a literature search on five databases, researchers found 413 studies. The next step was screening the article by reading the title and abstract, 385 studies were excluded. Then, the authors reviewed the full text of 28 articles for more detail evaluation. Finally, 10 studies were found that identified the needs of parents with critically ill babies in the NICU.

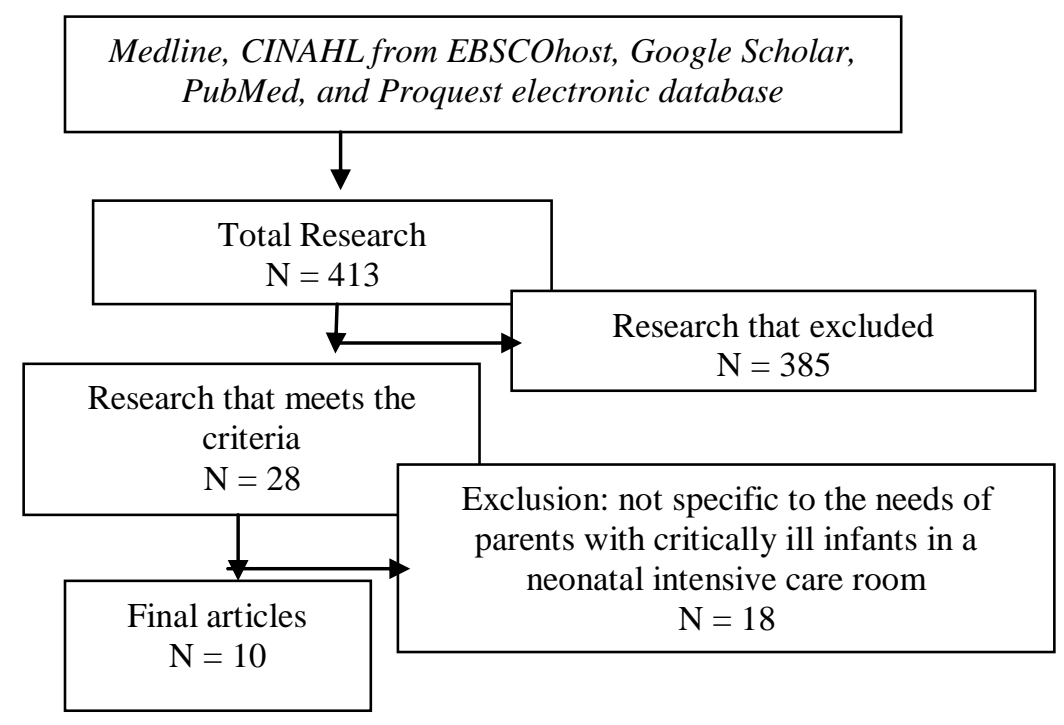

Figure 1 Flow Chart of Identification References for Literature Reviews 


\section{DISCUSSION}

\section{What are the needs of parents with critically ill babies in the neonatal intensive care unit?}

1. Positive acceptance and caring from nurses for babies and parents

Wigert et al. (2006) found that mothers felt useless and helpless in the intensive care room. They perceived that their babies belong to health workers. This was one cause of mother's negative feelings. As a result, nurses should encourage the mother to participate in caring for their babies. Nurses should have a positive perception that mothers are able to take care of their babies with nurses' supervision. Parents felt helpless when they were not involved in taking care of their babies (Cleveland, 2008).

Parents had assumed that nurses' acceptance or positive behavior were the most important needs of parents in the neonatal intensive care room (Cleveland, 2008; Mundy, 2010; Sikorova \& Kucova, 2012; Ward, 2012). Positive behavior from nurses would help mothers in reducing stress because their baby was hospitalized in the NICU (Sikorova \& Kucova, 2012). In opposite, when the relationship between mother and nurse was not well established, mothers perceived that they have lost their rights, this situation would increase maternal stress, and then, mothers preferred to make a distance with nurses (Cleveland, 2008). Parents had an intuition about whether someone really cares about their baby (Ward, 2012). It is important for parents to see that nurses provide comfort and care to their babies.

2. Accurate information, effective communication, and involvement in the decision making related to the baby's conditions

Parents with critically ill babies who were hospitalized in the NICU expected an accurate information, easy to understand, and sustainable (Mok \& Leung, 2006; Clevaland, 2008; Mundy, 2010; Ward, 2012). In addition, parents should be involved in the decision making process regarding their babies' conditions. Parents would be stressed when they did not obtain complete and accurate information about their babies (Cleveland, 2008). This finding in line with Arockiasamy, Holsti, and Albersheim's (2008) study which found that parental needs consist of the need for consistent information and an effective communication about their babies. Counseling was one of the interventions to communicate and establish therapeutic relationships between 
parents and nurses (Coscia et al., 2010). A good communication would be affected mothers' positive feelings.

Parents need a therapeutic relationship with nurses (Wigert et al., 2006). A good relationship between parents and nurses in the NICU should be improved by presenting and involving parents in caring processes, having a clear and open communication, and involving parents in the decision making (Latour et al., 2010). Nurses should be able to give a positive or negative influence on the development of the relationship between parents and babies. Mother felt that she had to ask permission from nurses when she wanted to interact with her baby and to be able to treat her baby. As a result, the mother considered the importance to establish a therapeutic relationship with nurses in providing care for their babies (Cleveland, 2008).

\section{Feeling confident and trusting about the best care for their babies}

Sikorova and Kucova (2012) and Musabirema et al. (2015) found that parents had experience of high stress, especially when they separated from their newborn baby, they felt unable to protect the baby from painful procedures and unable to take care the baby. To overcome with these feelings, Hurst (2001) in Cleveland (2008), Mundy (2010), and Ward (2012)'s studies found that parents' awareness was performed by monitoring their babies' conditions, gathering information, and reflecting on the mother's feelings about the condition of her baby. Mothers aware of hazardous situations, such as continuity of poor health services, lack of attention to their babies, and sometimes parents suspected that the treatment for their babies was inappropriate.

Parents had the need to protect their babies from harm by watching over their babies all the time (Mundy, 2010). Parents tried to ensure that the care given to their babies was the right procedures. By establishing a trust relationship between parents and nurses would help parents to feel relax (Cleveland, 2008; Mundy, 2010). In addition, Alves et al. (2016) and the research of Baia, Alves, Amorim, Fraga, and Silva (2015) in Portugal showed that Parents had the need of assurance related to an optimal care for their babies. The most important of parents' need was closeness to their infants. Parents supervised their babies by making contact via telephone to the NICU and by being present when the baby obtained certain treatments or medical procedures. Those were parents' techniques to protect their babies (Cleveland, 2008; Mundy, 2010). 


\section{Parents make contact with their babies}

The need to make strong contact with the baby was identified as an important need for parents (Orapiriyakul et al., 2007; Cleveland, 2008; Ward, 2012). According to Wigert et al.'s (2006) study revealed that babies had abilities to respond to their environment, including interaction with mothers. When this ability is limited, it would impact on the baby's negative emotional development. When a baby needs treatments in the NICU, this would be complicated contact between mother and baby. Some nurses gave a limit on mother's and baby interaction, and limit for mother's opportunity to stay with her baby. These actions affected parents' anger and frustration, especially mothers (Cleveland, 2008).

Guillaume et al.'s (2013) study described that father's actions to close with his baby by sending good words and seeing him from a distance. While mother tends to touch her baby through physical contact. There are two aspects that influence this behaviour, first is the caring behavior of nurses to infants and parents. The second is a good communication between health workers and parents that would reduce parents' stress and give more opportunity for parents and baby's interactions. A good communication was proven as health workers' support to parents that would strengthen parents and baby's interaction.

5. Parents' involvement in caring for their babies with the guidance and supervision of nurses

According to the family centered care services, the critical child care services are not only focused on the children life saving, but also provide nursing care for families, especially parents. Nurses who work in the NICU would encourage parents to be involved in the caring processes of their babies (Sikorova \& Kucova, 2012; Ward, 2012). Nurses should facilitate parents by performing kangaroo care and skin-to-skin contact programs between parents and infants; baby massage; and involving parents in meeting to discuss babies' daily need, such as bathing, giving milk, and changing diapers (Ward, 2012). These activities should be guided and supervised by nurses.

Having an opportunity to practice new skills in helping nurses to take care of their babies were identified as an important aspect for parents in the NICU. It would be increased positive interaction between parents and babies and increased their confidence 
in taking care of babies with nurses' supervision (Cleveland, 2008). Health education for parents about taking care of their babies in the NICU would improve their competences in caring for their babies (Ahn \& Kim, 2007).

\section{The NICU with a comfortable environment}

The creation of a therapeutic relationship between parents and nurses is an important priority in the NICU. Nurses needed to provide an enabling environment and non-judgemental to parents in developing their roles as parents (Clevaland, 2008; Ward, 2012). Nurses are very important to be able to create an environment that would meet the special needs of each parent and empower parents in caring for their babies.

Parents also need to feel welcome and comfortable when in the NICU, as result education, learning, and training programs for parents about new skills in caring their babies will succeed. Nurses should provide support in encouraging parents to be involved in caring for their babies so it would improve parents' experience in taking care of their babies. From the first time the baby hospitalization in the NICU, all care should be focused on achieving successful discharge planning when the baby returns home (Cleveland, 2008). The support provided by nurses for parents is very important so it would help parents to meet their needs.

Nurses should continually identify the needs of parents in the NICU. This should be a policy in the hospital service unit related to ensuring the needs of parents in receiving a complete and an accurate information about the conditions of their babies. Effective cooperation between nurses, doctors, and other staff would help parents to play an active role in making decisions regarding their babies. Creating and providing emotional support between parents and nurses, it would help in reducing parents' stress levels. Nurses should also pay attention to several factors that would be affected by parental needs. The results of Wang et al.'s (2016) study revealed that the sex of parents and previous experience in visiting a neonatal intensive care room had a significant effect on parental needs. In addition, unrestricted access and open visit policy in the NICU is necessary to ensure that parents are able to stay near their infants and to meet parents' need related to the interaction between parents and baby (Cleveland 2008, Wang et al. , 2016) 


\section{CONCLUSION}

Every parent has a different priority for the six needs. Identifying the needs of parents with critically ill babies in the NICU should be the focus of the nurse's in performing nursing care using the family centered care approach. Nurses have a responsibility to provide effective evidence-based practice to meet the needs of parents. Nurses play a key role in supporting parents to meet their needs related to caring for their babies in the NICU and influencing effective relationships between parents and their babies.

\section{NURSING IMPLICATIONS}

The implications of this literature reviews for nurses roles related to health professionals' support for parental needs in the NICU, including providing clear and accurate information about the condition of the baby, and developing a collaboration with parents and other health teams when making decisions relating to the care of the baby. Other support are creating emotional comfort and supportive neonatal intensive care environment to help parents in building trust, giving parents unlimited access to visit their babies and applying open visitation if possible, integrating the family centered care approach in the nursing care, helping parents to participate in providing care for their babies, and providing support and facilitate in establishing the formation of support groups among parents.

Doctors and nurses in the NICU should identify issues that develop in neonatal intensive care related to clinical practices. This very important to the advancement of the professions' services and to identify the needs of parents. Doctors and nurses would provide an appropriate support to meet parents' need, improve parental satisfaction, and improve the quality of neonatal life. Sometimes there were different perceptions between nurses and parents about the needs of parents with babies in the NICU. So identifying parental's needs with critically ill infants in the NICU should be carried out by nurses, and then nurses would provide support to meet their needs.

\section{REFERENCES}

Ahn, Y-M., \& Kim, N-H. (2007). Parental perception of neonates, parental stres and education for NICU parents. Asian Nursing Research, 1(3), 199-210.

Akbarbegloo, M., Valizadeh, L., \& Asadollahi M.I. (2009), Mothers and nurses viewpoint on importance and amount of nursing supports for parents with 
hospitalized premature infants in Neonatal Intensive Care Unit. Iranian Journal of Critical Care Nursing Summer, 2(2), 71-74.

Alves, E., Severo, M., Amorim, M., Grande, C., \& Silva, S. (2016). A short form of the neonatal intensive care unit family needs inventory. J Pediatr (Rio J), 92, 73---80. http://dx.doi.org/10.1016/j.jped.2015.04.010.

Arockiasamy, V., Holsti, L., \& Albersheim, A. (2008). Fathers' experiences in the Neonatal Intensive Care Unit: A search for control. Pediatrics, 12(2).

Baia, I., Alves, E., Amorim, M., Fraga, S., \& Silva, S. (2015). Parental needs and stress in Neonatal Intensive Care Units: Effect of data collection period. Arquivos de Medicina, 29(6), 160-162.

Byers, J.F., Linda, B.L., Francis, J., Kaigle, K., Lutz, N.H., Waddell, T., \& Diaz, A.L. (2006). A quasi-experimental trial on individualized, developmentally supportive family-centered care. JOGNN, 35, 105-115; 2006. DOI: 10.1111/J.1552-6909.2006.00002.x.

Cleveland, L.M. (2008). Parenting in the Neonatal Intensive Care Unit. The Association of Women's Health, Obstetric and Neonatal Nurses, JOGNN, 37(6), 666-691. DOI: $10.1111 /$ j.1552-6909.2008.00288.x.

Coscia, A., Bertino, E., Tonetto, P., Giuliani, F., Varalda, A., Di Nicola, P., \& ... Fabris, C. (2010). Communicative strategies in a Neonatal Intensive Care Unit. The Journal Of Maternal-Fetal \& Neonatal Medicine, 23, 311-13. doi:10.3109/14767058.2010.509911.

Guillaume, S., Michelin, N. Amrani, E., Benier, B., Durrmeyer, X., Lescure, S., \& Bony, C. (2013). Parents' expectations of staff in the early bonding process with their premature babies in the intensive care setting: A qualitative multicenter study with 60 parents. BMC Pediatrics, 13(18). Available at: http://www.biomedcentral.com/1471-2431/13/18.

Hiromi. (2011). Predictors of nurses' family-centered care practises in the Neonatal Intensive Care Unit. Japan Journal of Nursing Science, 8, 57-65. doi:10.1111/j.1742-7924.2010.00159.x.

Latour, J.M., Hazelzet, J.A., Duivenvoorden, H.J., \& Van Goudoever, J.B. (2010). Perceptions of parents, nurses, and physicians on Neonatal Intensive Care Practices. Journal of Pediatrics, 157(2):215-220.

Maghaireh, D.F.A., Abdullah, K.L., Chong, R.M.C.C., Chua, R.N.Y.P., \& Kawafha, M.M.A. (2017). Stress, anxiety, depression and sleep disturbance among Jordanian mothers and fathers of infants admitted to neonatal intensive care unit: a preliminary Study. Journal of Pediatric Nursing, 36, 132-140. https://doi.org/10.1016/j.pedn.2017.06.007. 
Mattsson, J., Forsner, M., Castrén, M., \& Arman, M. (2013). Caring for children in Pediatric Intensive Care Units: An observation study focusing on nurses' concerns. Nursing Ethics, 20(5), 528-538. doi:10.1177/0969733012466000.

Mok, E., \& Leung, S. (2006). Nurses as providers of support for mothers of premature infants. Children and Families, 15, 726-734.

Mundy, C.A. (2010). Assessment of family needs in Neonatal Intensive Care Units. Am J Crit Care, 19:156-163 doi: 10.4037/ajcc2010130.

Musabirema, P., Brysiewicz, P. \& Chipps, J., 2015, Parents perceptions of stress in a neonatal intensive care unit in Rwanda. Curationis 38(2), Art. \#1499, 8 pages. http://dx.doi.org/10.4102/ curationis.v38i2.1499.

O’Brien, K., Bracht, M., Macdonell, K., McBride, T., Robson, R., O’Leary, L., Christie, K., et al. (2013). A pilot cohort analytic study of family integrated care in a Canadian Neonatal Intensive Care Unit. BMC Pregnancy and Childbirth, 13(Suppl 1):S12. Available at: http://www.biomedcentral.com/14712393/13/S1/S12.

Orapiriyakul, R., Jirapaet, V., \& Rodcumdee, D. (2007). Struggling to get connected: the process of maternal attachment to the preterm infant in the Neonatal Intensive Care Unit. Thai Journal of Nursing Research, 11(4), 251-264.

Sikorova, L. \& Kucova, J. (2012). The needs of mothers to newborns hospitalised in intensive care units. Biomed, 156(4):330-336.

Skene, C., Franck, L., Curtis, P., \& Gerrish, K. (2012). Parental involvement in neonatal comfort care. JOGNN, 41(6), 786-797. DOI: 10.1111/j.15526909.2012.01393.x.

Soury-Lavergne, A., Hauchard, I., Dray, S., Baillot, M-L., Bertholet, E., Clabault, K., et al. (2011). Carer perspectives: Survey of caregiver opinions on the practicalities of family-centred care in intensive care units. Journal of Clinical Nursing, 21, 10601067. doi: 10.1111/j.1365-2702.2011.03866.x.

Trajkovski, S., Schmied, V., Vickers, M., \& Jackson, D. (2012). Clinical issues neonatal nurses' perspectives of family-centred care: A qualitative study. Journal of Clinical Nursing, 21, 2477-2487, doi: 10.1111/j.1365-2702.2012.04138.x.

Vance, C.A.E. (2011). Measuring Neonatal Quality of Life (NeoQOL) for critically-ill newborns in Neonatal Intensive Care Units. Dissertation, University of Washington. Available at search.proquest.com.

Vaškelyte, A. \& Butkevičienè, R. (2010). Needs of parents with premature newborns in the Neonatal Intensive Care Unit: Parents' and nurses' perceptions. Medicina (Kaunas), 46 (1 priedas). 
Wang, L., He, J.L., \& Fei, S.L. (2016). Perceived needs of parents of premature infants in NICU. Western Journal of Nursing Research.

Ward, K. (2001). Perceived needs of parents of critically ill infants in a Neonatal Intensive Care Unit (NICU). Pediatr Nurs, 27(3):281-286.

. (2012). 10 most important needs of parents of premature babies in the NICU. Family and Parenting, Last Update on Juli 15, 2012.

Wigert, H., Johansson, R., Berg, M., \& Hellström, A.L. (2006). Mothers' experiences having their newborn child in a Neonatal Intensive Care Unit. Scandinavian Journal of Caring Sciences, 20, 35-41. 